OPEN ACCESS

Edited by:

Giovanna Suzzi,

Università di Teramo, Italy

Reviewed by:

Milan Zivko Baltić, Faculty of Veterinary Medicine,

University of Belgrade, Serbia Giorgia Perpetuini,

Università di Teramo, Italy

${ }^{*}$ Correspondence:

Tze Y. Thung

upmtty@yahoo.com

Son Radu

son@upm.edu.my

Specialty section:

This article was submitted to

Food Microbiology,

a section of the journal

Frontiers in Microbiology

Received: 22 July 2017 Accepted: 26 December 2017

Published: 11 January 2018

Citation:

Thung TY, Radu S, Mahyudin NA, Rukayadi Y, Zakaria Z, Mazlan N, Tan BH, Lee E, Yeoh SL, Chin YZ,

Tan CW, Kuan $\mathrm{CH}$, Basri DF and Wan Mohamed Radzi CWJ (2018)

Prevalence, Virulence Genes and Antimicrobial Resistance Profiles of Salmonella Serovars from Retail Beef in Selangor, Malaysia.

Front. Microbiol. 8:2697.

doi: 10.3389/fmicb.2017.02697

\section{Prevalence, Virulence Genes and Antimicrobial Resistance Profiles of Salmonella Serovars from Retail Beef in Selangor, Malaysia}

\author{
Tze Y. Thung ${ }^{1 *}$, Son Radu ${ }^{1,2 \star}$, Nor A. Mahyudin ${ }^{1}$, Yaya Rukayadi ${ }^{1}$, Zunita Zakaria ${ }^{3}$, \\ Nurzafirah Mazlan ${ }^{4}$, Boon H. Tan ${ }^{5}$, Epeng Lee ${ }^{1,2}$, Soo L. Yeoh ${ }^{1,2}$, Yih Z. Chin ${ }^{1}$, \\ Chia W. Tan ${ }^{1}$, Chee H. Kuan ${ }^{6}$, Dayang F. Basri ${ }^{7}$ and Che W. J. Wan Mohamed Radzi ${ }^{8}$ \\ ${ }^{1}$ Department of Food Science, Faculty of Food Science and Technology, Universiti Putra Malaysia, Serdang, Malaysia, \\ ${ }^{2}$ Laboratory of Food Safety and Food Integrity, Institute of Tropical Agriculture and Food Security (ITAFoS), Universiti Putra \\ Malaysia, Serdang, Malaysia, ${ }^{3}$ Department of Veterinary Pathology and Microbiology, Faculty of Veterinary Medicine, \\ Universiti Putra Malaysia, Serdang, Malaysia, ${ }^{4}$ Department of Diagnostic and Allied Science, Faculty of Health and Life \\ Science, Management and Science University, Shah Alam, Malaysia, ${ }^{5}$ Division of Applied Biomedical Sciences and \\ Biotechnology, School of Health Sciences, International Medical University, Kuala Lumpur, Malaysia, ${ }^{6}$ Department of \\ Agricultural and Food Science, Faculty of Science, Universiti Tunku Abdul Rahman, Kampar, Malaysia, ${ }^{7}$ Novel Antibiotic \\ Laboratory, School of Diagnostic and Applied Health Sciences, Faculty of Health Sciences, Universiti Kebangsaan Malaysia, \\ Kuala Lumpur, Malaysia, ${ }^{8}$ Department of Science and Technology Studies, Faculty of Science, University of Malaya, Kuala \\ Lumpur, Malaysia
}

The aim of the present study was to investigate the prevalence of Salmonella spp., Salmonella Enteritidis and Salmonella Typhimurium in retail beef from different retail markets of Selangor area, as well as, to assess their pathogenic potential and antimicrobial resistance. A total of 240 retail beef meat samples (chuck $=60$; rib $=60$; round $=60$; sirloin $=60$ ) were randomly collected. The multiplex polymerase chain reaction ( $\mathrm{mPCR}$ ) in combination with the most probable number (MPN) method was employed to detect Salmonella spp., S. Enteritidis and S. Typhimurium in the meat samples. The prevalence of Salmonella spp., S. Enteritidis and S. Typhimurium in 240 beef meat samples were $7.50,1.25$, and $0.83 \%$, respectively. The microbial loads of total Salmonella was found in the range of $<3$ to $15 \mathrm{MPN} / \mathrm{g}$. Eight different serovars of Salmonella were identified among the 23 isolates, and S. Agona was the predominant serovar (26.09\%). Interestingly, all the Salmonella isolates were resistant to penicillin, erythromycin and vancomycin, but the sensitivity was observed for tetracycline, gentamicin and amoxicillin/clavulanic acid. All 23 isolates were resistant to at least three antibiotics. Two S. Typhimurium isolates (8.70\%) exhibited the highest multiple antibiotic resistance (MAR) index value of 0.56 which shown resistance to nine antibiotics. PCR analysis of virulence genes showed that all Salmonella isolates (100\%) were positive for the invA gene. Meanwhile, pefA was only identified in S. Enteritidis and $S$. Typhimurium. The findings in this study indicate that retail beef products tested were widely contaminated with multi-drug resistant (MDR) Salmonella and various virulence genes are present among the isolated Salmonella serovars.

\footnotetext{
Keywords: beef meat, Salmonella, multiplex PCR, prevalence, antimicrobial resistance, virulence gene
} 


\section{INTRODUCTION}

The intestinal epithelium infection known as salmonellosis is caused by the genus Salmonella. The major pathogenic serovars of Salmonella enterica that infect humans from a variety of different food products include Salmonella Enteritidis and Salmonella Typhimurium (Kramarenko et al., 2014; Yang et al., 2016; Ed-dra et al., 2017). In the USA over 40,000 salmonellosis cases are reported each year and foods of animal origin are considered to be the most likely source of Salmonella (Finstad et al., 2012). It is well known that human Salmonella infections are associated with many different kinds of food, including beef meat and beef meat products (Brichta-Harhay et al., 2008; Sallam et al., 2014). Hence, the presence of Salmonella in beef at the slaughter level and at the market is a significant food safety risk.

Sensitive and specific methods with shorter turnaround time for the detection and identification of Salmonella are needed to reduce testing-related laboratory costs. Therefore, multiplex polymerase chain reaction (mPCR) uses few pairs of primers simultaneously detecting different pathogens in the same samples has the potential as a reliable and effective method (Pui et al., 2011). Previously, a detection method consist of mPCR and the most probable number (MPN) method has successfully been performed to detect and identify $S$. Enteritidis and $S$. Typhimurium in chicken meat (Thung et al., 2016). Indeed, the mPCR-MPN method has widely been used to detect and enumerate food-borne pathogens such as Campylobacter spp. (Chai et al., 2007), Listeria monocytogenes (Kuan et al., 2013) and Vibrio parahaemolyticus (Tan et al., 2017). Recently, gold nanoparticle-aptamer-based localized surface plasmon resonance (LSPR) sensing chip was developed to enable the ultra-sensitive and selective detection of $S$. Typhimurium in pork meat (Oh et al., 2017).

In general, bacterial virulence factors have a crucial role for systemic infections. The pathogenicity of Salmonella strains has been related to numerous virulence genes present in the chromosomal Salmonella pathogenicity islands (SPIs) (Nayak et al., 2004). Genes such as invA and hilA, found in SPI, allow Salmonella to invade epithelial cells (Cardona-Castro et al., 2002; Nayak et al., 2004). Besides, Salmonella outer proteins (sops) (SPI effector protein) encoded by sop gene have relevance to Salmonella virulence (Huehn et al., 2010). Meanwhile, the plasmid encoded fimbriae ( $p e f A$ ) gene contributes to the adhesion of Salmonella to epithelial cells (Murugkar et al., 2003). Other chromosomal gene like stn, codes for enterotoxin production has been shown to be a causative agent of diarrhea (Huehn et al., 2010). In addition, virulence plasmids carrying virulence genes such as the spv operon (Salmonella plasmid virulence) contribute to the colonization of deeper tissues among other functions (Swamy et al., 1996).

To date, the emergence and spread of antimicrobial resistance among zoonotic Salmonella has become a public health threat (Sallam et al., 2014). Importantly, Salmonella strains having "clinically important resistance" to some agents like extendedspectrum cephalosporins and fluoroquinolones, have been isolated from livestock ( $\mathrm{Li}$ et al., 2013). In most developing countries, misuse and overuse of antibiotics has contributed to the increasing trend of multi-resistance in Salmonella (Eddra et al., 2017). In Selangor (center of Peninsular Malaysia), although some reports were found based on the prevalence of Salmonella in different types of foods, but limited information on the surveillance study of Salmonella spp., S. Enteritidis and S. Typhimurium in beef meat at retail level are available. Therefore, the aim of this study was to assess the prevalence, virulence genes and antimicrobial resistance of Salmonella serovars isolated from retail beef meat in Selangor area.

\section{MATERIALS AND METHODS}

\section{Collection of Meat Sample}

Four different parts of beef meat samples ( chuck $=60$; rib $=60$; round $=60$; sirloin $=60$ ) with a total number of 240 were collected from retail markets (wet markets and hypermarkets) in Selangor area over 9 months period from September 2014 to May 2015 (approximately 25 to 27 samples per month). The retail meat samples were kept in sterile stomacher bags and transferred to the laboratory for further analysis.

\section{Enrichment and Most Probable Number (MPN) Method}

Ten gram of meat sample was homogenized for $50 \mathrm{~s}$ using a stomacher after added in $90 \mathrm{~mL}$ of sterile buffered peptone water (BPW) (Merck, Darmstadt, Germany). Then, the suspension was diluted up to 1,000-fold with 10-fold serial. Later, MPN method (three-tube) was performed by transferring $1 \mathrm{~mL}$ of each dilution into three replicate tubes with $10 \mathrm{~mL}$ of Rappaport-Vasiliadis (RV) broth (Merck, Darmstadt, Germany) each, and followed by overnight incubation at $37^{\circ} \mathrm{C}$ under aerobic conditions. The turbid MPN tubes were selected for subsequent DNA extraction using the boiled-cell method as described previously (Chai et al., 2007).

\section{Multiplex PCR Conditions}

For mPCR detection, three primer pairs were used to identify randomly selected-sequence of unknown function gene (429 bp) for Salmonella spp., sdfI gene (304 bp) for S. Enteritidis, and $f l i C$ gene $(620 \mathrm{bp})$ for $S$. Typhimurium. The sequences of the primer pair used for targeting random sequence were $5^{\prime}$-GCCAACCATTGCTAAATTGGCGCA- $3^{\prime}$ and $5^{\prime}$ GGTAGAAATTCCCAGCGGGTACTGG-3' (Soumet et al., 1999), whereas the primer pair used for targeting the $s d f I$ gene were 5'-TGTGTTTTATCTGATGCAAGAGG-3' and 5'-TGAACTACGTTCGTTCTTCTGG-3' (Alvarez et al., 2004), followed by the primer pair used for targeting the fliC gene were 5'-CGGTGTTGCCCAGGTTGGTAAT-3' and 5'-ACTGGTAAAGATGGCT-3' (Soumet et al., 1999). We optimized the $\mathrm{mPCR}$ reaction conditions by a series of preliminary experiments so that the three independent PCR reactions can be performed in the same tube with the detection limit of $10^{5} \mathrm{cfu} / \mathrm{mL}$ (data not shown). The optimized mPCR reaction mixture $(25 \mu \mathrm{L})$ contained $2 \mu \mathrm{L}$ of DNA template, $5 \mu \mathrm{L}$ of $5 \times$ PCR buffer, $2.5 \mu \mathrm{L}$ of $25 \mathrm{mM} \mathrm{MgCl}_{2}, 0.5 \mu \mathrm{L}$ of 10 $\mathrm{mM}$ deoxynucleotide triphosphate (dNTP), $0.5 \mu \mathrm{L}$ of $1.2 \mu \mathrm{M}$ primer mix and $14.2 \mu \mathrm{L}$ of deionized water. The mixture was 
then treated with $0.3 \mu \mathrm{L}(1.5 \mathrm{U})$ Taq DNA polymerase. PCR amplification was performed in triplicate with the following conditions: initial denaturation at $94^{\circ} \mathrm{C}$ for $2 \mathrm{~min}, 30$ cycles of denaturation at $94^{\circ} \mathrm{C}$ for $45 \mathrm{~s}$, annealing at $53^{\circ} \mathrm{C}$ for $1 \mathrm{~min}$, extension at $72^{\circ} \mathrm{C}$ for $1 \mathrm{~min}$ and final extension at $72^{\circ} \mathrm{C}$ for 7 min. The positive controls used were $S$. Typhimurium ATCC 14028 and S. Enteritidis ATCC 13076. Escherichia coli ATCC 25922 was used as a negative control.

\section{Isolation and Identification of Salmonella}

The turbid MPN tubes were confirmed to be Salmonella by plating on selective CHROMagar Salmonella (CHROMagar Microbiology, Paris, France) and Xylose Lysine Deoxycholate (XLD) (Merck, Darmstadt, Germany) agar plates, and incubated at $37^{\circ} \mathrm{C}$ for $24 \mathrm{~h}$. All the Salmonella isolates were then serotyped by slide agglutination using polyvalent "O" and " $\mathrm{H}$ " antisera (BD, Franklin Lakes, USA) at Veterinary Research Institute (VRI), Ipoh, Malaysia in accordance with the Kauffmann-White scheme.

\section{Antimicrobial Resistance Profiles}

The antimicrobial susceptibility was evaluated according to Clinical and Laboratory Standarts Institude (2012) by using disc diffusion method. Briefly, isolates were cultured aerobically in 10 mL Mueller-Hinton (MH) broth (Merck, Darmstadt, Germany) at $37^{\circ} \mathrm{C}$ for $24 \mathrm{~h}$. Overnight cultures, grown on $\mathrm{MH}$ broth (OD adjusted to 0.5 MacFarland unit), were swabbed evenly with sterile non-toxic cotton swab on $\mathrm{MH}$ agar plates and left to dry for 2 to $4 \mathrm{~min}$. Then, antimicrobial sensitivity discs were placed on the culture by using a disk dispenser and incubated at $37^{\circ} \mathrm{C}$ for $24 \mathrm{~h}$. The tested antimicrobials were amoxicillin/clavulanic acid (AMC, $30 \mu \mathrm{g}$ ), amoxycillin (AML, $30 \mu \mathrm{g}$ ), ceftazidime (CAZ, $30 \mu \mathrm{g}$ ), cephazolin (KZ, $30 \mu \mathrm{g}$ ), ciprofloxacin (CIP, 5 $\mu \mathrm{g}$ ), erythromycin (E, $15 \mu \mathrm{g})$, chloramphenicol (C, $30 \mu \mathrm{g}$ ), ampicillin (AMP, $10 \mu \mathrm{g}$ ), penicillin (, $10 \mu \mathrm{g}$ ), streptomycin $(\mathrm{S}, 10 \mu \mathrm{g})$, tetracycline (TE, $30 \mu \mathrm{g})$, kanamycin $(\mathrm{K}, 30 \mu \mathrm{g})$, gentamicin (CN, $10 \mu \mathrm{g}$ ), vancomycin (VA, $30 \mu \mathrm{g}$ ), nalidixic acid (NA, $30 \mu \mathrm{g}$ ), and suphamethoxazole/trimethoprim (SXT, $25 \mu \mathrm{g}$ ) (Oxoid, Hamphire, United Kingdom). The multiple antibiotic resistance (MAR) index was calculated as "a/b," where "a" the number of antibiotics for a particular isolate was resistant and " $b$ " the total number of antibiotics tested (Krumperman, 1983).

\section{Detection of Virulence Genes}

All Salmonella isolates collected in this study were screened for the presence of virulence genes using PCR. The primers, the size in base pairs of the respective amplification products and the references used for detection of six virulence genes are presented in Table 1. The virulence genes under study were invA, pefA, hilA, $s o p B$, stn, and $s p v C$. Positive (S. Typhimurium ATCC 14028 and $S$. Enteritidis ATCC 13076) and negative control (E. coli ATCC 25922) were conducted in the detection procedure. To evaluate the reproducibility of the experiments, PCR amplification and electrophoresis experiments were carried out in triplicate.

\section{Statistical Analysis}

All measurements were carried out in triplicate. Minitab (v. 14) statistical package (Minitab Inc., State College, PA) was used to determine if there was any significant difference between the prevalence of Salmonella in beef meat from wet market and hypermarket. For all analysis, $P<0.05$ was considered significant.

\section{RESULTS}

\section{Prevalence of Salmonella in Beef}

The target genes specific to Salmonella spp., S. Enteritidis and $S$. Typhimurium produced amplicons at 429, 304, and $620 \mathrm{bp}$, respectively. Figure 1 shows the result of gel electrophoresis comparing various combinations of the PCR primer sets and verifying the MPCR established for the current study consists of three independent and specific PCR reactions. Of the 240 retail beef meat samples tested, the contamination rates were $7.50 \%$ $(n=18), 1.25 \%(n=3)$, and $0.83 \%(n=2)$ for Salmonella spp., $S$. Enteritidis and $S$. Typhimurium, respectively (Table 2). Beef part round was the major reservoir for Salmonella, with prevalence rate of $16.67 \%(n=60)$. The prevalence of Salmonella spp. in wet markets $(10.00 \%)$ were significantly higher than hypermarkets $(5.00 \%)(P<0.05)$. As shown in Table 3 , the highest microbial loads of Salmonella was found in Salmonella spp. (15.0 MPN/g), followed by $S$. Enteritidis (3.6 MPN/g) and $S$. Typhimurium (3.6 MPN/g).

\section{Antimicrobial Resistance Profiles}

Antibiotic sensitivity testing was performed for the 23 isolated Salmonella strains, which included $S$. Enteritidis $(n=3)$, $S$. Typhimurium $(n=2), S$. Agona $(n=6), S$. Anatum $(n=3), S$. London $(n=3), S$. Newport $(n=3)$, S. Stanley $(n=1)$, and $S$. Weltevreden $(n=2)$. As shown in Table 4, three antibiotics gentamicin, amoxicillin/clavulanic acid, and tetracycline were effective $(100 \%)$ to all isolates. In this study, resistance to erythromycin, penicillin and vancomycin were seen in $100 \%$ of $S$. Enteritidis, $S$. Typhimurium, S. Agona, S. Anatum, $S$. London, $S$. Newport, $S$. Stanley and $S$. Weltevreden isolates. As shown in Table 5, the highest MAR index value of 0.56 was found in two $S$. Typhimurium isolates. Observation from the presence study indicated that all Salmonella isolates were multi-drug resistant (MDR) strains, which showed resistance to three antibiotics (penicillin, vancomycin and erythromycin) or more. Nine Salmonella isolates (39.13\%) mainly from S. Agona and $S$. Newport were resistant to four antibiotics, and three $S$. Enteritidis (13.04\%) were resistant to at least five of the antibiotics.

\section{Distribution of Virulence Genes among Salmonella Isolates}

All 23 Salmonella isolates were tested by PCR for the presence of virulence genes. The invasion gene operon invA was detected in all Salmonella isolates (Table 6). Regarding the different frequencies of $h i l A, \operatorname{sop} B$, and $\sin$ genes among different serovars, a clear difference was noticed in the occurrence of these genes among the isolates; $S$. London and $S$. Stanley did not show the 
TABLE 1 | PCR primers used for amplification of virulence genes in Salmonella isolates.

\begin{tabular}{|c|c|c|c|}
\hline Virulence genes & Primer sequence $\left(5^{\prime}-3^{\prime}\right)$ & Size (bp) & Reference \\
\hline invA & F- TATCGCCACGTTCGGCAA & 275 & Nayak et al., 2004 \\
\hline pefA & R- TCGCACCGTCAAAGGAACC & 700 & Murugkar et al., 2003 \\
\hline hilA & F- TGTTCCGGGCTTGTGCT & 854 & Cardona-Castro et al., 2002 \\
\hline $\operatorname{sop} B$ & R- CAGGGCATTTGCTGATTCTTCC & 517 & Huehn et al., 2010 \\
\hline sth & F- CGGAAGCTTATITGCGCCATGCTGAGGTAG & 617 & Murugkar et al., 2003 \\
\hline \multirow[t]{7}{*}{ spvC } & R- GCATGGATCCCCGCCGGCGAGAT TGTG & 669 & Swamy et al., 1996 \\
\hline & F- TCAGAAGRCGTCTAACCACTC & & \\
\hline & R- TACCGTCCTCATGCACACTC & & \\
\hline & F- TTGTGTCGCTATCACTGGCAACC & & \\
\hline & R- ATTCGTAACCCGCTCTCGTCC & & \\
\hline & F- CGGAAATACCATCAAATA & & \\
\hline & R- CCCAAACCCATACTTACTCTG & & \\
\hline
\end{tabular}

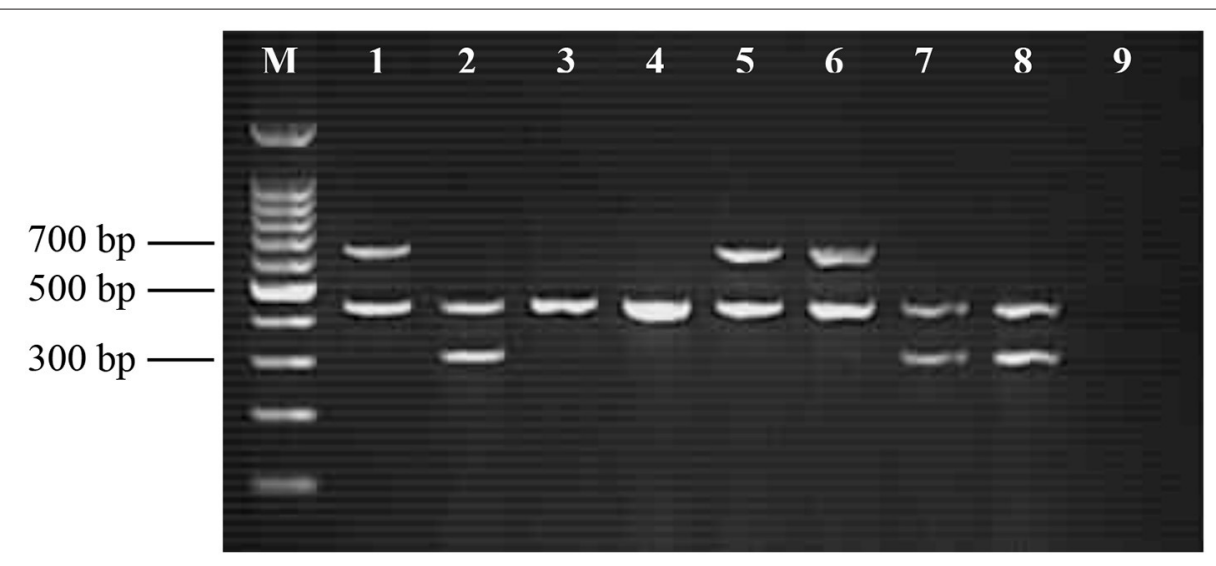

FIGURE 1 | Representative amplification of random sequence, sdfl gene and fliC gene for identification of Salmonella spp. (429 bp), S. Enteritidis (304 bp) and S. Typhimurium (620 bp), respectively. Lane M: 100-bp DNA ladder; Lane 1: mixture of Salmonella spp. and S. Typhimurium (positive); Lane 2: Salmonella spp. and S. Enteritidis (positive); Lane 3 to Lane 8: meat samples examined; and Lane 9: negative control.

presence of $s o p B$ gene. Furthermore, pefA gene was present in 3 of the 23 isolates tested (13.04\%), comprising S. Enteritidis (one isolate) and $S$. Typhimurium (two isolates). Overall, the serovars tested showed at least three virulence-associated genes.

\section{DISCUSSION}

Results of investigations of retail beef meat samples do provide an estimate of the prevalence of Salmonella in retail shops. The high incidence of Salmonella in wet markets of the present study indicated poor sanitary condition in the food processing environment and lack of better personal hygiene of food handlers during product preparation. High incidence of Salmonella in wet markets was observed in the previous study of Thung et al. (2016), who found higher prevalence of Salmonella in retail chicken meat samples. An additional factor underlying potential differences in prevalence between wet markets and hypermarkets was that the storage temperature of the samples (Donado-Godoy et al., 2012). Meanwhile, the presence of Salmonella in retail beef meat might be due to the production system and conditions, hygienic slaughter, and transport before sale. In this study, the incidence of Salmonella in beef meat samples $(9.58 \%, n=240)$ was higher than the incidence $(2.16 \%, n=417)$ in Poland (Wieczorek and Osek, 2013) and less than the incidence (39.87\%, $n=158$ ) in North Vietnam (Thai et al., 2012). This could be due to the geographical variation such as climate and feed. On the other hand, prevalence of Salmonella has been reported in other food products in Malaysia. For example, Salmonella spp. and $S$. Typhimurium were detected in sliced fruits (such as papaya, watermelon, mango, sapodilla, jackfruit, dragon fruit and honeydew) (Pui et al., 2011), and vegetables (such as cabbage, carrot, capsicum, cucumber, lettuce and tomato) (Elexson et al., 2011). Besides, Najwa et al. (2015) have shown that Salmonella spp., S. Typhimurium and $S$. Enteritidis were detected in different types of local salad known as ulam (such as kacang botol, kacang panjang, pegaga nyonya, and selom).

In the present study, a combined MPN-mPCR was used to quantify the microbial load (MPN/g) which can facilitate the enumeration of Salmonella spp., S. Enteritidis and $S$. Typhimurium in the meat samples within a short period. The 
TABLE 2 | Prevalence of Salmonella spp., Salmonella Enteritidis and Salmonella Typhimurium in beef meat samples using MPN-mPCR method.

\begin{tabular}{|c|c|c|c|c|c|c|c|c|}
\hline \multirow[t]{2}{*}{ Beef part } & \multicolumn{4}{|c|}{ Wet markets } & \multicolumn{4}{|c|}{ Hypermarkets } \\
\hline & $n^{\mathrm{a}}$ & Salmonella spp. & S. Enteritidis & S. Typhimurium & $n$ & Salmonella spp. & S. Enteritidis & S. Typhimurium \\
\hline Chuck & 30 & $3(10.0 \%)^{b}$ & $0(0.0 \%)$ & $0(0.0 \%)$ & 30 & $2(6.7 \%)$ & $0(0.0 \%)$ & $0(0.0 \%)$ \\
\hline Rib & 30 & 3 (10.0\%) & $0(0.0 \%)$ & 0 (0.0\%) & 30 & $0(0.0 \%)$ & $0(0.0 \%)$ & $0(0.0 \%)$ \\
\hline Round & 30 & 4 (13.3\%) & 1 (3.3\%) & 1 (3.3\%) & 30 & 2 (6.7\%) & 1 (3.3\%) & 1 (3.3\%) \\
\hline Total & 120 & 12 (10.0\%) & $2(1.7 \%)$ & $1(0.8 \%)$ & 120 & $6(5.0 \%)$ & $1(0.8 \%)$ & $1(0.8 \%)$ \\
\hline
\end{tabular}

a Number of samples.

${ }^{b}$ Percentage of positive samples.

TABLE 3 | Microbial loads of Salmonella spp., Salmonella Enteritidis and Salmonella Typhimurium (MPN/g) in beef meat samples using MPN-mPCR method.

\begin{tabular}{|c|c|c|c|c|c|c|c|c|c|c|c|c|c|c|c|c|c|c|}
\hline \multirow[t]{2}{*}{ Beef part } & \multicolumn{9}{|c|}{ Wet markets } & \multicolumn{9}{|c|}{ Hypermarkets } \\
\hline & $\operatorname{Min}^{a}$ & Med $^{\mathbf{b}}$ & $\operatorname{Max}^{C}$ & Min & Med & Max & Min & Med & Max & Min & Med & Max & Min & Med & Max & Min & Med & Max \\
\hline Chuck & $<3$ & $<3$ & 7.4 & $<3$ & $<3$ & $<3$ & $<3$ & $<3$ & $<3$ & $<3$ & $<3$ & 3.6 & $<3$ & $<3$ & $<3$ & $<3$ & $<3$ & $<3$ \\
\hline Rib & $<3$ & $<3$ & 7.4 & $<3$ & $<3$ & $<3$ & $<3$ & $<3$ & $<3$ & $<3$ & $<3$ & $<3$ & $<3$ & $<3$ & $<3$ & $<3$ & $<3$ & $<3$ \\
\hline
\end{tabular}

${ }^{a}$ Minimum MPN/g value.

${ }^{b}$ Median MPN/g value.

${ }^{c}$ Maximum MPN/g value.

TABLE 4 | Antimicrobial susceptibility pattern of Salmonella isolates.

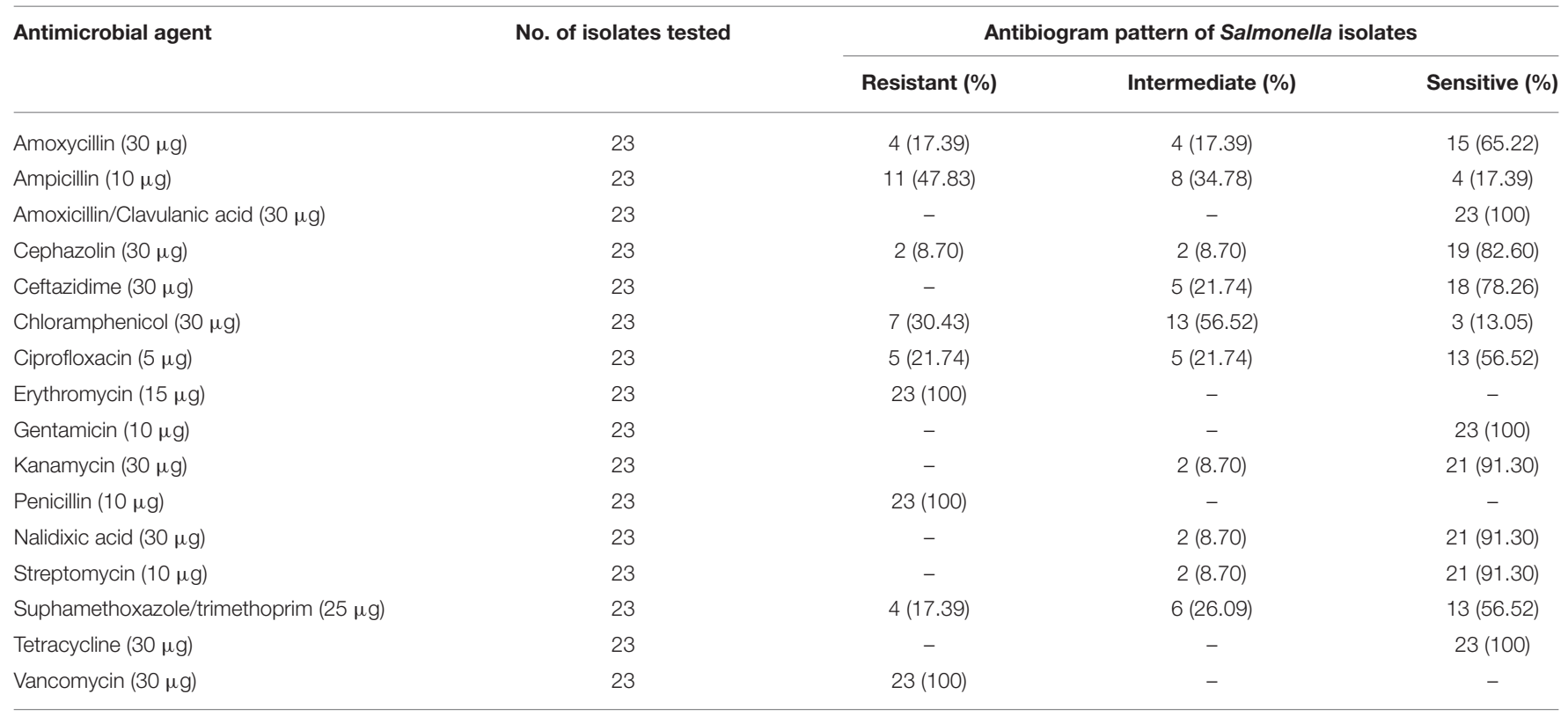

molecular amplification techniques can overcome the limitation of detecting viable but non-culturable (VBNC) cells with providing high specificity and sensitivity (Pui et al., 2011). The procedure of the MPN-mPCR should be familiar to laboratory personnel since it has been extensively used in academic research as well as in industrial settings. Previous studies have 
TABLE 5 | The antibiotic resistance profile patterns and multiple antibiotic resistance (MAR) index of Salmonella isolates.

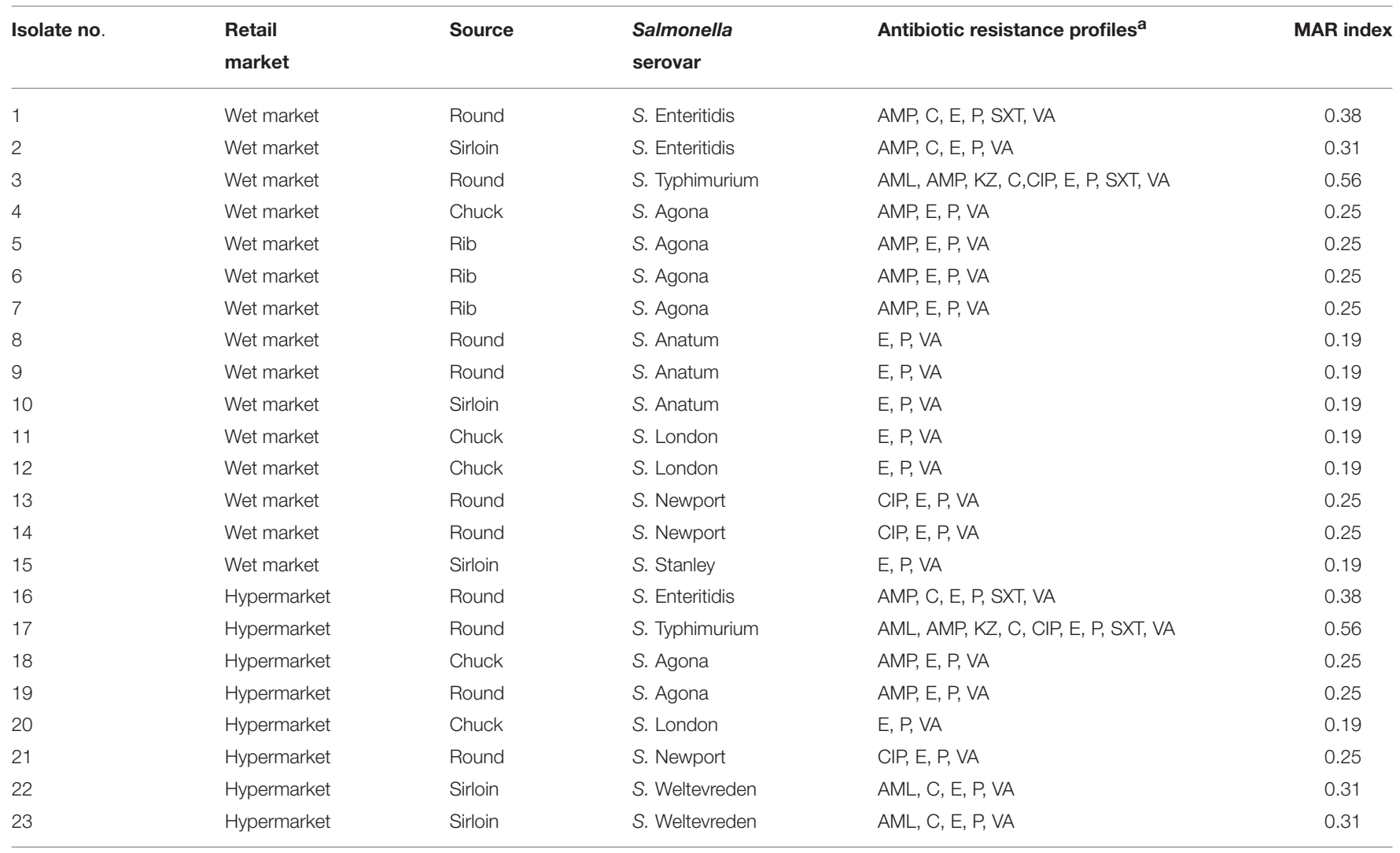

${ }^{a} A M L$, Amoxycillin; AMP, Ampicillin; KZ, Cephazolin; C, Chloramphenicol; CIP, Ciprofloxacin; E, Erythromycin; P, Penicillin; SXT, Suphamethoxazole/trimethoprim; VA, Vancomycin.

TABLE 6 | Virulence genes profiles of Salmonella isolates.

\begin{tabular}{|c|c|c|c|c|c|c|c|c|c|}
\hline \multirow[t]{2}{*}{ Gene } & \multicolumn{8}{|c|}{ Number of Salmonella serovars positive for virulence genes } & \multirow{2}{*}{$\begin{array}{c}\text { Total (\%) } \\
\text { (23) }\end{array}$} \\
\hline & $\begin{array}{l}\text { S. Enteritidis } \\
\text { (3) }\end{array}$ & $\begin{array}{l}\text { S. Typhimurium } \\
\text { (2) }\end{array}$ & $\begin{array}{l}\text { S. Agona } \\
\text { (6) }\end{array}$ & $\begin{array}{l}\text { S. Anatum } \\
\text { (3) }\end{array}$ & $\begin{array}{l}\text { S. London } \\
\text { (3) }\end{array}$ & $\begin{array}{l}\text { S. Newport } \\
\text { (3) }\end{array}$ & $\begin{array}{l}\text { S. Stanley } \\
\text { (1) }\end{array}$ & $\begin{array}{l}\text { S. Weltevreden } \\
\text { (2) }\end{array}$ & \\
\hline $\operatorname{inv} A$ & 3 & 2 & 6 & 3 & 3 & 3 & 1 & 2 & $23(100)$ \\
\hline pefA & 1 & 2 & 0 & 0 & 0 & 0 & 0 & 0 & $3(13.04)$ \\
\hline sth & 3 & 1 & 3 & 1 & 2 & 3 & 1 & 2 & $16(69.57)$ \\
\hline spvC & 0 & 0 & 0 & 0 & 0 & 0 & 0 & 0 & $0(0)$ \\
\hline
\end{tabular}

described detection methods that successfully combined MPN with mPCR to enumerate bacteria such as Campylobacter, Listeria monocytogenus, and Vibrio parahaemolyticus in samples (Kuan et al., 2017; Premarathne et al., 2017; Tan et al., 2017). Worth to note that beef meat products by their nature, undergo extensive processing and handling during their production, may also increase the risk of contamination (Thung et al., 2016). Typically, improper or ineffective cleaning of chopping boards, tables and knives does play a role in harboring and multiplying the organism. Cross-contamination may occur when microorganisms are transferred from one surface to another, possibly leading to contamination of other safe meat or clean equipment. Salmonella contamination was common in retail meats such as beef, pork and lamb, which could be a potential vehicle for transmitting Salmonella to humans (Yang et al., 2010). Thus, implementation and maintenance of some control measures like the good manufacturing practices (GMP) and hazard analysis and critical control point (HACCP), as well as further strengthening the education of food processors will be necessary, for reducing Salmonella contamination.

Due to clinical significance, determining or Salmonella resistance or otherwise to antimicrobial agents is critical for 
treatment during outbreaks. High resistance of Salmonella isolates to erythromycin, penicillin and vancomycin in this finding are of clinical concern and could be the result of widespread use of these antibiotics in Selangor area. Similarly, high percentage of penicillin and erythromycin resistance were observed in different Salmonella serovars which isolated from retail meat products such as beef burger, ground beef and fresh beef (Sallam et al., 2014). Interestingly, there were no Salmonella serovars resistant to amoxicillin/clavulanic acid, ceftazidime, gentamicin, kanamycin, nalidixic acid, streptomycin, and tetracycline. In contrast, resistance to tetracycline was observed among the serovars of $S$. Enteritidis and $S$. Typhimurium isolated from retail beef meat samples (Yang et al., 2010). Previously, a study in China demonstrated that all the Salmonella strains $(n=83)$ were sensitive to amoxicillin/clavulanic acid, while 98.80 and $92.77 \%$ were observed for gentamicin and tetracycline, respectively (Dong et al., 2014). In fact, MDR Salmonella serovars are considered to be more virulent than non-MDR Salmonella (Nayak et al., 2004; Dong et al., 2014). High percentages of antimicrobial resistant Salmonella serovars from retail meat products have been reported worldwide by several researchers (Yang et al., 2010; Thai et al., 2012; Sallam et al., 2014). In Malaysia, such observation was also reported by Geidam et al. (2012), where they were able to detect MDR Salmonella in the poultry environment in Selangor region. In this study, MDR Salmonella isolates are prevalent in both retail markets. Hence, more attention should be focused on the supervision and control of antimicrobial use, typically in the agriculture and human health care sectors in Malaysia.

Accordingly, the virulence of bacteria is influenced by both antimicrobial resistance and the presence of virulence genes (Huehn et al., 2010; Dong et al., 2014). The emergence of MDR strains of Salmonella are mainly based on the factors of genetic and biochemical mechanisms in order to enhance their survivability by preserving their drug resistance genes (Yang et al., 2010). Regarding the virulence factors that were analyzed, S. Enteritidis, S. Typhimurium, S. Agona, S. Anatum, $S$. Newport, and $S$. Weltevreden isolates showed a broader range of pathogenicity determinants as compared to other serovars. The most common virulence gene which present in Salmonella, invA gene, was used as PCR target gene for detection of Salmonella (Nayak et al., 2004; Dong et al., 2014). On the other hand, an OmpR/ToxR transcriptional regulator encoded

\section{REFERENCES}

Alvarez, J., Sota, M., Vivanco, A. B., Perales, I., Cisterna, R., Rementeria, A., et al. (2004). Development of a multiplex PCR technique for detection and epidemiological typing of Salmonella in human clinical samples. J. Clin. Microbiol. 42, 1734-1738. doi: 10.1128/JCM.42.4.1734-1738.2004

Brichta-Harhay, D. M., Guerini, M. N., Arthur, T. M., Bosilevac, J. M., Kalchayanand, N., Shackelford, S. D., et al. (2008). Salmonella and Escherichia coli O157:H7 contamination on hides and carcasses of cull cattle presented for slaughter in the United States: an evaluation of prevalence and bacterial loads by immunomagnetic separation and direct plating methods. Appl. Environ. Microbiol. 74, 6289-6297. doi: 10.1128/AEM.00700-08 by the hilA gene to activate the expression of invasion genes was shown to play an important role in Salmonella virulence (Cardona-Castro et al., 2002). In this study, the PCR screening using hilA-targeted Salmonella-specific primers showed a clear abundance of this virulence gene was detected in 19 of 23 analyzed strains (82.61\%), irrespective of their serovars. In addition, similar results have been reported by Murugkar et al. (2003) who found that the chromosomally encoded virulent stn gene was widely distributed in all the isolated serovars. This strengthens to our present finding; the stn gene was prevalent among the isolated Salmonella serovars by PCR-based assay (69.57\%). Several studies have shown that the Salmonella virulence plasmid plays an important role in human disease (Swamy et al., 1996).

In summary, this study has shown that a combined MPNmPCR method was a reliable and useful for rapid screening of Salmonella from retail beef meat. Our results indicate that retail beef meat act as reservoirs in harboring multiple Salmonella serovars, where cross-contamination might be occurred during processing and at the retail level. S. Agona was the most common serotype found in retail beef. Moreover, the recovered Salmonella isolates exhibiting multi-drug resistant and multiple virulence genes, which constitute a possible risk to humans from consumption of these products. Therefore, it is important to manage the use of antimicrobial agents in livestock now, to prevent the acquisition and increased resistance to recent molecules in order to fight against the vertical and horizontal transfer of MDR strains. Alternatively, it is necessary for developing more effective intervention strategies such as green control method using bacteriophages as controlling measure in the food chain in order to reduce the risk of food-borne diseases.

\section{AUTHOR CONTRIBUTIONS}

All authors listed have made a substantial, direct and intellectual contribution to the work, and approved it for publication.

\section{ACKNOWLEDGMENTS}

This research was funded by Fundamental Research Grant Scheme from the Ministry of Education, Malaysia (FRGS 5524559) and the Putra Grant of Universiti Putra Malaysia (GPIPS 9438703). 
Dong, P., Zhu, L., Mao, Y., Liang, R., Niu, L., Zhang, Y., et al. (2014). Prevalence and profile of Salmonella from samples along the production line in Chinese beef processing plants. Food Control. 38, 54-60. doi: 10.1016/j.foodcont.2013.09.066

Ed-dra, A., Filali, F. R., Karraouan, B., El Allaoui, A., Aboulkacem, A., and Bouchrif, B. (2017). Prevalence, molecular and antimicrobial resistance of Salmonella isolated from sausages in Meknes, Morocco. Microb. Pathog. 105, 340-345. doi: 10.1016/j.micpath.2017.02.042

Elexson, N., Chai, L. C., Pui, C. F., Tunung, R., Ubong, A., Tuan Zainazor, T. C., et al. (2011). Simultaneous detection of Salmonella spp., Salmonella Enteritidis and Salmonella Typhimurium in raw salad vegetables and vegetarian burger patties. Food Nutr. Sci. 2, 1077-1081. doi: 10.4236/fns.2011.210144

Finstad, S., O’Bryan, C. A., Marcy, J. A., Crandall, P. G., and Ricke, S. C. (2012). Salmonella and broiler processing in the United States: relationship to foodborne salmonellosis. Food Res. Int. 45, 789-794. doi: 10.1016/j.foodres.2011.03.057

Geidam, Y. A., Zakaria, Z., Aziz, S. A., Bejo, S. K., Abu, J., and Omar, S. (2012). High prevalence of multi-drug resistant bacteria in selected poultry farms in Selangor, Malaysia. Asian J. Anim. Vet. Adv. 7, 891-897. doi: 10.3923/ajava.2012.891.897

Huehn, S., La Ragione, R. M., Anjum, M., Saunders, M., Woodward, M. J., Bunge, C., et al. (2010). Virulotyping and antimicrobial resistance typing of Salmonella enterica serovars relevant to human health in Europe. Foodborne Pathog. Dis. 7, 523-535. doi: 10.1089/fpd.2009.0447

Kramarenko, T., Nurmoja, I., Karssin, A., Meremae, K., Horman, A., and Roasto, M. (2014). The prevalence and serovar diversity of Salmonella in various food products in Estonia. Food Control. 42, 43-47. doi: 10.1016/j.foodcont.2014.01.032

Krumperman, P. H. (1983). Multiple antibiotic resistance indexing of Escherichia coli to indentify high-risk sources of fecal contamination of foods. Appl. Environ. Microbiol. 46, 165-170.

Kuan, C. H., Rukayadi, Y., Ahmad, S. H., Wan Mohamed Radzi, C. W. J., Thung, T. Y., Premarathne, J. M. K. J. K., et al. (2017). Comparison of the microbiological quality and safety between conventional and organic vegetables sold in Malaysia. Front. Microbiol. 8:1433. doi: 10.3389/fmicb.2017.01433

Kuan, C. H., Wong, W. C., Pui, C. F., Mahyudin, N. A., Tang, J. Y. H., Nishibuchi, M., et al. (2013). Prevalence and quantification of Listeria monocytogenes in beef offal at retail level in Selangor, Malaysia. Braz. J. Microbiol. 44, 1169-1172. doi: 10.1590/S1517-83822014005000002

Li, R., Lai, J., Wang, Y., Liu, S., Li, Y., Liu, K., et al. (2013). Prevalence and characterization of Salmonella species isolated from pigs, ducks and chickens in Sichuan Province, China. Int. J. Food Microbiol. 163, 14-18. doi: 10.1016/j.ijfoodmicro.2013.01.020

Murugkar, H. V., Rahman, H., and Dutta, P. K. (2003). Distribution of virulence genes in Salmonella serovars isolated from man and animals. Indian J. Med. Res. $117,66-70$.

Najwa, M. S., Rukayadi, Y., Ubong, A., Loo, Y. Y., Chang, W. S., Lye, Y. L., et al. (2015). Quantification and antibiotic susceptibility of Salmonella spp., Salmonella Enteritidis and Salmonella Typhimurium in raw vegetables (ulam). Int. Food Res. J. 22, 1761-1769.

Nayak, R., Stewart, T., Wang, R. F., Lin, J., Cerniglia, C. E., and Kenney, P. B. (2004). Genetic diversity and virulence gene determinants of antibioticresistance Salmonella isolated from preharvest turkey production sources. Int. J. Food Microbiol. 91, 51-62. doi: 10.1016/S0168-1605(03)00330-1

Oh, S. Y., Heo, N. S., Shukla, S., Cho, H. J., Vilian, A. T. E., Kim, J., et al. (2017). Development of gold nanoparticle-aptamer-based LSPR sensing chips for the rapid detection of Salmonella Typhimurium in pork meat. Sci. Rep. 7:10130. doi: 10.1038/s41598-017-10188-2
Premarathne, J. M. K. J. K., Anuar, A. S., Thung, T. Y., Satharasinghe, D. A., Jambari, N. N., Abdul Mutalib, N. A., et al. (2017). Prevalence and antibiotic resistance against tetracycline in Campylobacter jejuni and C. coli in cattle and beef meat from Selangor, Malaysia. Front. Microbiol. 8:2254. doi: $10.3389 /$ fmicb. 2017.02254

Pui, C. F., Wong, W. C., Chai, L. C., Elexson, N., Farinazleen, M. G., Cheah, Y. K., et al. (2011). Simultaneous detection of Salmonella spp., Salmonella Typhi and Salmonella Typhimurium in sliced fruits using multiplex PCR. Food Control. 22, 337-342. doi: 10.1016/j.foodcont.2010.05.021

Sallam, K. I., Mohammed, M. A., Hassan, M. A., and Tamura, T. (2014). Prevalence, molecular identification and antimicrobial resistance profile of Salmonella serovars isolated from retail beef products in Mansoura, Egypt. Food Control. 38, 209-214. doi: 10.1016/j.foodcont.2013.10.027

Soumet, C., Ermel, G., Rose, N., Rose, V., Drouin, P., Salvat, G., et al. (1999). Evaluation of a multiplex PCR assay for simultaneous identification of Salmonella sp., Salmonella Enteritidis and Salmonella Typhimurium from environmental swabs of poultry houses. Lett. Appl. Microbiol. 28, 113-117. doi: 10.1046/j.1365-2672.1999.00488.x

Swamy, S. C., Barnhart, H. M., Lee, M. D., and Dreesen, D. W. (1996). Virulence determinantsinvA and spvC in Salmonellae isolated from poultry products, wastewater, and human sources. Appl. Environ. Microbiol. 62, 3768-3771.

Tan, C. W., Malcolm, T. T. H., Kuan, C. H., Thung, T. Y., Chang, W. S., Loo, Y. Y., et al. (2017). Prevalence and antimicrobial susceptibility of Vibrio parahaemolyticus isolated from Short Mackerels (Rastrelliger brachysoma) in Malaysia. Front. Microbiol. 8:1087. doi: 10.3389/fmicb.2017.01087

Thai, T. H., Hirai, T., Lan, N. T., Shimada, A., Ngoc, P. T., and Yamaguchi, R. (2012). Antimicrobial resistance of Salmonella serovars isolated from beef at retail markets in the North Vietnam. J. Vet. Med. Sci. 74, 1163-1169. doi: 10.1292/jvms.12-0053

Thung, T. Y., Mahyudin, N. A., Basri, D. F., Wan Mohamed Radzi, C. W., Nakaguchi, Y., Nishibuchi, M., et al. (2016). Prevalence and antibiotic resistance of Salmonella Enteritidis and Salmonella Typhimurium in raw chicken meat at retail markets in Malaysia. Poult. Sci. 95, 1888-1893. doi: 10.3382/ps/pew144

Wieczorek, K., and Osek, J. (2013). Prevalence and characterisation of Salmonella in slaughtered cattle and beef in Poland. Bull. Vet. Inst. Pulawy. 57, 607-611. doi: 10.2478/bvip-2013-0103

Yang, B., Qu, D., Zhang, X., Shen, J., Cui, S., Shi, Y., et al. (2010). Prevalence and characterization of Salmonella serovars in retail meats of marketplace in Shaanxi, China. Int. J. Food Microbiol. 141, 63-72. doi: 10.1016/j.ijfoodmicro.2010.04.015

Yang, X., Huang, J., Wu, Q., Zhang, J., Liu, S., Guo, W., et al. (2016). Prevalence, antimicrobial resistance and genetic diversity of Salmonella isolated from retail ready-to-eat foods in China. Food Control. 60, 50-56. doi: 10.1016/j.foodcont.2015.07.019

Conflict of Interest Statement: The authors declare that the research was conducted in the absence of any commercial or financial relationships that could be construed as a potential conflict of interest.

The reviewer GP and handling Editor declared their shared affiliation.

Copyright (c) 2018 Thung, Radu, Mahyudin, Rukayadi, Zakaria, Mazlan, Tan, Lee, Yeoh, Chin, Tan, Kuan, Basri and Wan Mohamed Radzi. This is an open-access article distributed under the terms of the Creative Commons Attribution License (CC $B Y)$. The use, distribution or reproduction in other forums is permitted, provided the original author(s) or licensor are credited and that the original publication in this journal is cited, in accordance with accepted academic practice. No use, distribution or reproduction is permitted which does not comply with these terms. 